\title{
POLIEMBRIONIA E ATRIBUTOS MORFOLÓGICOS DE SEMENTES DE PORTA-ENXERTOS DE CITROS ${ }^{1}$
}

\author{
FERNANDA EMILIA VITAL DE OLIVEIRA DUARTE², DAIANA DOS REIS BARROS ${ }^{3}$, \\ EDUARDO AUGUSTO GIRARDI ${ }^{4}$, WALTER DOS SANTOS SOARES FILHO ${ }^{5}$, \\ ORLANDO SAMPAIO PASSOS ${ }^{6}$
}

RESUMO - A poliembrionia é um caráter fundamental no melhoramento genético e na multiplicação comercial de porta-enxertos de citros. Este trabalho avaliou as relações entre poliembrionia e diferentes atributos morfológicos de sementes de 12 genótipos de citros selecionados como porta-enxertos. Foram analisadas 50 sementes por genótipo, quanto a massa, altura, largura, número de embriões, taxa de poliembrionia, grau de dificuldade de extração da testa, coloração da semente, estimada por um matiz das duas notas de cores predominantes, e razão de cor, calculada pela divisão entre a menor e a maior nota do matiz. Os resultados foram submetidos à análise de variância, comparando-se as médias pelo teste de Scott-Knott e determinando-se os coeficientes de correlação de Pearson entre as variáveis $(P \leq 0,05)$. Os porta-enxertos apresentaram atributos de sementes distintos, podendo ser agrupados em três classes de poliembrionia, destacando-se três seleções de limoeiro 'Cravo' com poliembrionia inferior a 50\%, citrandarins como totalmente poliembriônicos e outros híbridos de Poncirus trifoliata com taxas baixas a intermediárias. O grau de dificuldade de extração da testa foi maior nas sementes menores. Na maioria dos genótipos avaliados, o número de embriões por semente correlacionou- se positivamente à massa, altura e largura de sementes e negativamente à razão de cor, sugerindo que a análise de coloração de sementes inteiras pode ser ferramenta alternativa para uma avaliação visual rápida da ocorrência de poliembrionia.

Termos para indexação: Citrus spp., análise de cor da semente, melhoramento genético, morfologia da semente, poliembrionia, propagação.

\section{POLYEMBRYONY AND MORPHOLOGICAL SEED TRAITS IN CITRUS ROOTSTOCKS}

\begin{abstract}
Seed polyembryony is an important trait for breeding and commercial multiplication of citrus rootstocks. This study evaluated relationships of polyembryony with different morphological seed traits of 12 citrus genotypes selected as rootstocks. The following traits were evaluated individually on 50 seeds per genotype: seed mass, height, width and embryo number, polyembryony level, difficulty for seed coat extraction, and seed color, which was estimated by a two-grade scale representing predominant colors on the endosperm. Data was submitted to variance analyses and the means were compared by the Scott-Knott Test $(P \leq 0.05)$. Pearson's Correlation Coefficients were determined among all variables for all genotypes and individually. Citrus rootstocks had significantly distinct seed traits and could be classified in three polyembryony groups, with three Rangpur lime selections presenting polyembryony lower than $50 \%$ and the citrandarins as totally polyembryonic. Other trifoliate hybrids showed low to intermediate polyembryony. Seed coat extraction was more difficult in smaller seeds. For majority of genotypes, the number of embryos in the seed had positive correlation to the seed mass, height and width and negative correlation to the color ratio, which was calculated by the division of the lowest and highest color grades. This result suggests that the whole seed color analysis may be an alternative method for a rapid visual evaluation of polyembryony manifestation.
\end{abstract}

Index terms: Citrus spp., genetic breeding, polyembriony, propagation, seed color analysis, seed morphology.

\footnotetext{
'(Trabalho 157-12). Recebido em: 16-05-2012. Aceito praa publicação em: 16-10-2012.

${ }^{2}$ Graduanda em Engenharia Agronômica, Universidade Federal Rural do Rio de Janeiro. E-mails: fernanda vital6@hotmail.com, daiana_barros606@hotmail.com. Primeira autora bolsista IC PROIC/DPPG-UFRRJ

${ }^{3}$ Eng. Agr., DSc. Fitotecnia, Professor Adjunto, Departamento de Fitotecnia, Instituto de Agronomia, Universidade Federal Rural do Rio de Janeiro. E-mail: girardi@cnpmf.embrapa.br

${ }^{4}$ Eng. Agr., DSc. Genética e Melhoramento Vegetal, Pesquisador A, Embrapa Mandioca e Fruticultura. E-mail: wsoares@cnpmf. embrapa.br

${ }^{5}$ Eng. Agr., MSc. Genética e Melhoramento Vegetal, Pesquisador B, Embrapa Mandioca e Fruticultura. E-mail: orlando@cnpmf. embrapa.br
} 


\section{INTRODUÇÃO}

O Brasil detém cerca de $50 \%$ da produção mundial de laranja (Citrus sinensis (L.) Osbeck) e $85 \%$ do mercado mundial de suco processado (NEVES et al., 2010). O limoeiro 'Cravo' (Citrus limonia Osbeck) é o porta-enxerto presente em cerca de $70 \%$ do parque citrícola brasileiro, devido principalmente à sua tolerância ao vírus da tristeza (Citrus tristeza virus - CTV) e à deficiência hídrica, bem como pela precocidade da produção (POMPEU JÚNIOR, 2005). No entanto, a presença de doenças que afetam esse porta-enxerto, como a gomose de Phytophthora spp., o declínio e a morte súbita dos citros (MSC), implica a necessidade de maior diversificação de variedades porta-enxerto no Brasil.

$\mathrm{Na}$ propagação dos citros, outros atributos são igualmente relevantes para a seleção de porta-enxertos, especialmente a poliembrionia das sementes (SOARES FILHO et al., 2003). A grande maioria das variedades cítricas produz sementes poliembriônicas derivadas do tecido nucelar do ovário circundante ao saco embrionário (ANDRADE et al., 2007). A embrionia adventícia esporofítica (poliembrionia), um tipo de apomixia (reprodução assexual por semente), é comum em muitos genótipos de citros e cujo controle genético é complexo, envolvendo pelo menos um gene (ALESA et al., 2010), sendo influenciado ainda por fatores bióticos e abióticos, como polinização e clima (GARCÍA et al., 1999). Além disso, sabe-se que um menor número de embriões por semente favorece o aumento do tamanho e a taxa de germinação do embrião zigótico (SOARES FILHO et al., 2000). Por outro lado, quanto mais alta a taxa de poliembrionia, maiores são as chances de se obter plantas de origem nucelar, clones da planta-matriz, sendo esse o objetivo na multiplicação comercial de porta-enxertos.

A coloração dos cotilédones pode ser utilizada para diferenciar embriões zigóticos de embriões nucelares (HUENO; HIRAI, 1983). Estudando cruzamentos controlados de citros, Vasquez Araújo et al. (1994) relataram que a coloração dos cotilédones varia com a natureza do embrião, sendo colorida em embriões zigóticos e branca em embriões nucelares. A cor dos cotilédones é um caráter controlado por um único gene em citros, sendo a coloração branca dominante (SHUNYUAN et al., 1994). Assim, a coloração das sementes, que resulta da combinação de cores dos cotilédones, poderia variar conforme a quantidade de embriões na semente, representando possível estimativa do grau de poliembrionia e para identificação do embrião zigótico.

Conhecer as relações entre poliembrionia e alguns atributos morfológicos das sementes pode auxiliar no processo de melhoramento genético de porta-enxertos efetuado, neste caso, via embrião zigótico (BOWMAN et al., 1995). Essas relações podem ainda favorecer o estabelecimento de práticas culturais no viveiro, como a classificação de sementes e práticas de semeadura, visando a otimizar o sistema de produção dos porta-enxertos, nesse caso visando à seleção da plântula originada do embrião nucelar (CASTLE, 1981). Este trabalho teve por objetivo a avaliação da poliembrionia de porta-enxertos comerciais de citros, bem como de alguns genótipos promissores, relacionando-a a atributos morfológicos das sementes.

\section{MATERIAL E MÉTODOS}

As análises foram realizadas entre agosto e dezembro de 2010, no Laboratório de Cultura de Tecidos Vegetais da Universidade Federal Rural do Rio de Janeiro, em Seropédica-RJ ( $22^{\circ} 44^{\prime} 38^{\prime \prime} \mathrm{S}$; $\left.43^{\circ} 42^{\prime} 28^{\prime \prime} \mathrm{W} ; 26 \mathrm{~m}\right)$. Os porta-enxertos avaliados foram trifoliata 'Flying Dragon' (Poncirus trifoliata (L.) Raf. var. monstrosa), tangerineira 'Sunki Tropical' (Citrus sunki (Hayata) hort ex Tanaka), limoeiro 'Cravo Santa Cruz' (C. limonia Osbeck), citrandarins 'Indio', 'Riverside' (C. sunki x $P$. trifoliata 'English') e 'San Diego' (C. sunki x $P$. trifoliata 'Swingle'), além dos híbridos HTR (híbrido trifoliado)-051, TSKC x (LCR x TR)-059, TSKC x CTSW-064 e TSKC x CTTR-002, considerados potenciais porta-enxertos, sendo que TSKC, LCR, TR, CTSW e CTTR correspondem, respectivamente, à tangerineira 'Sunki' comum, limoeiro 'Cravo', $P$. trifoliata, citrumelo (C. paradisi Macfad. x $P$. trifoliata) 'Swingle' e citrange $(C$. sinensis $\times$ P trifoliata) 'Troyer'. Estes genótipos foram obtidos ou introduzidos pelo Programa de Melhoramento Genético de Citros da Embrapa Mandioca e Fruticultura - PMG Citros, com os frutos coletados no Banco de Germoplasma de Citros da mesma instituição. Adicionalmente, avaliaram-se dois acessos de limoeiro 'Cravo' da Universidade Federal Rural do Rio de Janeiro, denominados ENA-01 e ENA-02, sendo os frutos coletados de matrizes em plantio comercial em Bom Jardim-RJ, selecionadas pela alta produção.

Sementes foram extraídas manualmente de 15-25 frutos típicos, maduros, colhidos em julho/ agosto de 2010, misturadas, dentro de cada genótipo, e lavadas em água corrente por uma hora. Em seguida, foram tratadas em solução de cal e água, mantida sobre agitador mecânico por 45 minutos para a retirada da mucilagem. As sementes foram 
dispostas à sombra por três dias e, após a secagem, eliminaram-se as sementes malformadas. Em seguida, as sementes foram tratadas com Captan $\AA$ a $1 \%$, armazenadas em sacos de papel coberto por filme plástico e enviadas ao laboratório, sendo mantidas a $5^{\circ} \mathrm{C}$ até as avaliações.

Uma amostra de 50 sementes de cada variedade ou híbrido foi obtida do total de sementes coletadas, avaliando-se, individualmente, em laboratório: massa, determinada em balança de precisão; altura e largura, medidas por paquímetro digital; aderência da testa (tegumento externo da semente), estimada pelo grau de dificuldade de extração manual, variando de 1 (fácil extração) a 3 (difícil extração), avaliada porque a extração da testa resulta em aumento da porcentagem e redução no tempo de germinação em viveiros (MOREIRA et al., 2010); coloração do endosperma da semente, determinada visualmente segundo uma escala de notas com matiz duplo, ou seja, discriminando-se as duas cores predominantes, separadas por uma barra (1 - branco; 2 - bege-claro; 3 - amarelo-claro; 4 - amarelo-escuro; 5 - bege-escuro; 6 - cinza; 7 verde-claro; 8 - verde; 9 - verde-escuro) adaptada de Jaskani et al.(2006); a razão de cor, obtida pela soma de todas as divisões entre a menor e a maior nota do matiz e dividido pelo número de sementes analisadas (50 sementes): [ $\sum$ (matiz 1/matiz 2) $] / 50$; taxa de poliembrionia $(\mathrm{P})$, com a média calculada pela percentagem de sementes contendo dois ou mais embriões e a frequência dada por código binário, sendo 0 monoembrionia e 1 poliembrionia (SOARES FILHO et al., 2003); e número de embriões por semente (NES), determinado por contagem direta dos cotilédones das sementes, com auxílio de bisturi sob lente de aumento $10 \mathrm{X}$.

Adotou-se o delineamento inteiramente casualizado, com uma semente por parcela, totalizando 50 repetições. Os resultados foram submetidos à análise de variância, e as médias foram comparadas pelo teste de Scott-Knott $(P$ $\leq 0,05)$, determinando-se ainda o coeficiente de correlação de Pearson entre os caracteres avaliados para o conjunto dos porta-enxertos e para cada genótipo individualmente. A razão de cor descrita anteriormente foi utilizada para estimar a correlação entre coloração e demais atributos das sementes.

\section{RESULTADOS E DISCUSSÃO}

Os porta-enxertos de citros apresentaram atributos de sementes bastante distintos entre si (Tabela 1). Sementes de seleções de limoeiro 'Cravo' apresentaram menor tamanho e maior dificuldade de extração da testa, enquanto sementes de citrandarins foram maiores. Apesar das sementes grandes, o trifoliata 'Flying Dragon' também apresentou dificuldade para a extração da testa. Neste caso, as sementes estavam visualmente desidratadas e notou-se que a extração dos tegumentos foi menos trabalhosa para porta-enxertos em que as sementes se mostravam visualmente mais túrgidas, independentemente de seu tamanho. Os coeficientes de variação $(\mathrm{CV})$ das variáveis contínuas altura e largura das sementes foram inferiores ao da massa de sementes (Tabela 1), sugerindo tamanho uniforme de sementes em cada genótipo. Por outro lado, em variáveis discretas, o $\mathrm{CV}$ foi elevado, pois as variações ocorreram na ordem de uma unidade e, assim, representam termos relativos elevados.

Estabeleceu-se uma escala de notas, variando de 1 a 9, conforme cores observadas nas sementes de citros amostradas (branco e tonalidades de bege, amarelo e verde). A escala seguiu um matiz duplo, ou seja, a combinação de duas notas, que representavam as duas cores predominantes na semente (JASKANI et al., 2006). Em geral, as cores distintas na semente relacionaram- se, respectivamente, ao maior par de cotilédones e aos cotilédones menores, sendo, pois, uma estimativa indireta de poliembrionia. Sementes com cores iguais no matiz indicaram um único par de cotilédones com cor uniforme. A razão de cor foi calculada pela divisão da menor nota pela maior nota e, portanto, quanto mais próxima de 1 , indicou uniformidade de coloração da semente e, possivelmente, presença de apenas um par de cotilédones ou monoembrionia. Contudo, em tangerineira 'Sunki Tropical' e trifoliateiro 'Flying Dragon', a razão de cor de sementes foi constante e próxima de 1, indicando cor uniforme dos cotilédones (Tabela 1), embora apresentem, respectivamente, alta e baixa taxa de poliembrionia (Tabela 2). A razão de cor poderá depender, assim, de outras condições, como posição dos embriões nucelares na semente ou diferença de tonalidades entre os cotilédones, o que pode explicar os coeficientes de variação observados neste trabalho. Mesmo assim, a razão de cor foi menor em portaenxertos de maior taxa de poliembrionia, como era esperado.

Os porta-enxertos avaliados podem ser agrupados em três classes de poliembrionia (Tabela 1): baixa (32\% a 52\%) - trifoliata 'Flying Dragon', clones de limoeiro 'Cravo' e os híbridos TSKC x CTTR-002 e TSKC x (LCR x TR)-059; média (86\% a 88\%)-HTR-051 e tangerineira 'Sunki Tropical'; e alta $(98 \%$ a $100 \%)$ - citrandarins 'Indio', 'Riverside' 
e 'San Diego' e o híbrido TSKC x CTSW-064. Classes semelhantes podem ser discriminadas para número médio de embriões por semente, sendo esse diretamente proporcional à taxa de poliembrionia (Tabelas 1 e 2). Resultados semelhantes são relatados em trabalhos anteriores (SOARES FILHO et al., 2000, 2002; SCHÄFER et al., 2005; PASSOS et al., 2006; MOREIRA et al., 2010) em tangerineiras, limoeiros e trifoliata, bem como em seus híbridos interespecíficos. Desta forma, em viveiros comerciais, o uso de duas ou mais sementes de limoeiro 'Cravo' e trifoliata 'Flying Dragon' por recipiente seria recomendável para aumentar a probabilidade de se obter ao menos um clone nucelar. Por outro lado, em programas de melhoramento, o uso desses genótipos como genitores femininos em hibridações controladas seria vantajoso, uma vez que resultam em menor produção de clones nucelares e, dessa maneira, maior facilidade em obtenção e seleção dos embriões zigóticos de interesse.

$\mathrm{Na}$ análise conjunta de todos os portaenxertos, o número de embriões por semente correlacionou- se positivamente com todos os atributos de tamanho de semente avaliados (massa, altura e largura) (Tabela 3). A massa correlacionou- se positivamente à altura e largura de semente, enquanto a razão de cor se correlacionou negativamente ao número de embriões por semente e à massa de sementes. Por outro lado, quando avaliados dentro de cada genótipo, os atributos de sementes selecionados neste trabalho não se correlacionaram ou apresentaram baixa correlação, mesmo quando se comparam genótipos semelhantes (Tabela 3), corroborando a grande variação de atributos de sementes em citros. Bowman et al. (1995) relataram correlação positiva entre massa e largura de sementes com poliembrionia em genótipos de citros, contudo em grau insuficiente para justificar a classificação de sementes por tamanho em viveiros comerciais.

Algumas relações específicas podem ser destacadas. Em tangerineira 'Sunki Tropical', observou-se relação inversa entre largura de semente e grau de dificuldade de extração da casca, sugerindo que o tamanho reduzido da semente nesta espécie dificultou sua manipulação e, consequentemente, a retirada da casca (Tabela 3). Essa condição é ainda mais evidente quando as sementes dos genótipos são analisadas em conjunto, evidenciando a maior dificuldade de extração de tegumento em genótipos com sementes menores, como as seleções de limoeiro 'Cravo' avaliadas (Tabelas 1 e 3), o que possivelmente exigirá trabalho adicional nos viveiros de citros.
Em limoeiro 'Cravo Santa Cruz' e citrandarins 'Indio' e 'San Diego', observou-se correlação positiva entre número de embriões por semente e variáveis de tamanho da semente (Tabela 3). Em HTR-051, essa relação deu- se apenas para a altura, ou seja, quanto maior a taxa de poliembrionia, maior foi a altura das sementes. A classificação de sementes por tamanho nesses genótipos, especialmente para o limoeiro 'Cravo' que apresenta taxa de poliembrionia inferior, poderia ser avaliada como prática em viveiros, visando a uniformizar a semeadura e reduzir o uso de sementes monoembriônicas. Contudo, o fato de não se constatar relação direta entre massa de semente e número de embriões em todos os porta-enxertos estudados sugere que a presença de um maior número de embriões na semente implique menor tamanho e massa individual do embrião e de seus cotilédones, resultando na mesma massa final de semente. Há uma relação inversa entre as porcentagens de poliembrionia e de embriões zigóticos de maior tamanho (SOARES FILHO et al., 2003).

Em limoeiro 'Cravo' ENA-02, houve correlação negativa entre o número de embriões na semente e a razão de cor da semente (Tabela 3). Relação similar foi observada nos porta-enxertos limoeiro 'Cravo Santa Cruz', HTR-051, citrandarin 'Riverside' e TSKC x CTSW-064. Somente para citrandarin 'Indio' verificou-se uma correlação positiva entre essas variáveis, e para trifoliata 'Flying Dragon' os coeficientes não foram estimados, pois a razão de cor não variou. Seguindo a metodologia adotada neste trabalho, os valores médios da razão de cor próximos a um significam coloração mais uniforme e indicariam a presença predominante de um único par de cotilédones e, assim, um único embrião. Essa condição foi corroborada pela correlação inversa observada entre a razão de cor e o número de embriões em diferentes genótipos, sugerindo que a análise de cor de sementes inteiras de citros possa ser investigada como ferramenta alternativa para avaliação visual rápida de poliembrionia, com possíveis aplicações práticas em viveiros e programas de melhoramento genético. 
TABELA 1 - Massa, altura, largura, grau de dificuldade de extração da testa (T), matiz de cores, razão de cor, taxa de poliembrionia (P) e número médio de embriões (NES) em sementes de portaenxertos de citros $(n=50)$. Seropédica-RJ,

\begin{tabular}{|c|c|c|c|c|c|c|c|c|}
\hline Porta-enxerto* & $\begin{array}{c}\text { Massa } \\
(\mathrm{g})\end{array}$ & $\begin{array}{l}\text { Altura } \\
------(m\end{array}$ & $\begin{array}{l}\text { Largura } \\
\text { m) ------ }\end{array}$ & $\mathrm{T}^{1}$ & $\begin{array}{l}\text { Matiz } \\
\text { de cor }\end{array}$ & $\begin{array}{l}\text { Razão } \\
\text { de cor }\end{array}$ & $\begin{array}{l}\mathrm{P}^{4} \\
(\%) \\
\end{array}$ & NES \\
\hline Limoeiro ‘Cravo’ ENA-01 & $0,06 \mathrm{f}$ & $9,1 \mathrm{e}$ & $3,35 \mathrm{~d}$ & $2,62 \mathrm{~b}$ & $3 / 8$ & $0,51 \mathrm{e}$ & 44,0 & $1,56 \mathrm{~d}$ \\
\hline Limoeiro ‘Cravo' ENA-02 & $0,09 \mathrm{e}$ & $10,5 \mathrm{~b}$ & $3,57 \mathrm{~d}$ & $2,82 \mathrm{a}$ & $3 / 8$ & $0,48 \mathrm{e}$ & 42,0 & $1,44 \mathrm{~d}$ \\
\hline Limão ‘Cravo' Santa Cruz & $0,06 \mathrm{f}$ & $9,4 \mathrm{~d}$ & $3,54 \mathrm{~d}$ & $2,58 \mathrm{~b}$ & $3 / 8$ & $0,58 \mathrm{~d}$ & 52,0 & $1,64 \mathrm{~d}$ \\
\hline Tangerina 'Sunki' Tropical & $0,10 \mathrm{~d}$ & $10,0 \mathrm{c}$ & $4,70 \mathrm{~b}$ & $1,14 \mathrm{f}$ & $8 / 9$ & $0,89 \mathrm{a}$ & 88,0 & $3,20 \mathrm{c}$ \\
\hline Trifoliata 'Flying Dragon' & $0,18 \mathrm{a}$ & $10,6 \mathrm{~b}$ & $4,11 \mathrm{c}$ & $2,80 \mathrm{a}$ & $3 / 4$ & $0,75 \mathrm{~b}$ & 32,0 & $1,34 \mathrm{~d}$ \\
\hline HTR-051 & $0,10 \mathrm{~d}$ & $9,6 \mathrm{~d}$ & $4,70 \mathrm{~b}$ & $1,42 \mathrm{e}$ & $5 / 7$ & $0,64 \mathrm{c}$ & 86,0 & $2,74 \mathrm{c}$ \\
\hline Citrandarin 'Indio' & $0,18 \mathrm{a}$ & $11,1 \mathrm{a}$ & $5,90 \mathrm{a}$ & $1,02 \mathrm{f}$ & $7 / 8$ & $0,72 \mathrm{~b}$ & 98,0 & $4,94 \mathrm{~b}$ \\
\hline Citrandarin 'Riverside' & $0,16 \mathrm{~b}$ & $10,6 \mathrm{~b}$ & $5,78 \mathrm{a}$ & $1,94 \mathrm{~d}$ & $3 / 8$ & $0,40 \mathrm{f}$ & 100,0 & $4,76 \mathrm{~b}$ \\
\hline Citrandarin 'San Diego' & $0,14 \mathrm{c}$ & $11,1 \mathrm{a}$ & $5,72 \mathrm{a}$ & $1,08 \mathrm{f}$ & $3 / 8$ & $0,38 \mathrm{f}$ & 100,0 & $6,02 \mathrm{a}$ \\
\hline TSKC x (LCR x TR)-059 & $0,16 \mathrm{~b}$ & $11,0 \mathrm{a}$ & $4,86 \mathrm{~b}$ & $1,18 \mathrm{f}$ & $3 / 7$ & $0,63 \mathrm{c}$ & 52,0 & $1,88 \mathrm{~d}$ \\
\hline TSKC x CTSW-064 & $0,06 \mathrm{f}$ & $7,8 \mathrm{f}$ & $4,59 \mathrm{~b}$ & $2,28 \mathrm{c}$ & $3 / 7$ & $0,44 \mathrm{f}$ & 100,0 & $4,26 \mathrm{~b}$ \\
\hline TSKC x CTTR-002 & $0,10 \mathrm{~d}$ & $10,7 \mathrm{~b}$ & $4,30 \mathrm{c}$ & $1,02 \mathrm{f}$ & $3 / 7$ & $0,50 \mathrm{e}$ & 44,0 & $1,62 \mathrm{~d}$ \\
\hline $\mathrm{CV}(\%)$ & 23,8 & 10,6 & 15,8 & 25,5 & - & 27,3 & - & 41,9 \\
\hline
\end{tabular}

Médias seguidas por letras diferentes na coluna diferem entre si, pelo Teste de $\operatorname{Scott-Knott~}(P \leq 0,05)$.

*onde TSKC, LCR, TR, CTSW, CTTR e HTR correspondem, respectivamente, a tangerineira 'Sunki' comum, limoeiro 'Cravo' Poncirus trifoliata, citrumelo 'Swingle', citrange ‘Troyer' e híbrido trifoliado.

${ }^{1}$ Estimado em escala de notas variando de 1 (dificuldade mínima) a 3 (dificuldade máxima).

${ }^{2}$ Estimado pelo matiz mais frequente das duas cores predominantes na semente ( 1 - branco; 2 - bege- claro; 3 - amarelo-claro; 4 amarelo- escuro; 5 - bege- escuro; 6 - cinza; 7 - verde- claro; 8 - verde; 9 - verde- escuro).

${ }^{3}$ Calculada pela soma de todas as divisões entre a menor e a maior nota do matiz e dividido pelo número de sementes analisadas (50 sementes).

${ }^{4}$ Calculada pela relação entre número de sementes contendo dois ou mais embriões pelo número total de sementes avaliadas.

TABELA 2 - Distribuição (\%) de sementes de porta-enxertos cítricos em classes de número de embrião por semente $(\mathrm{n}=50)$. Seropédica-RJ.

\begin{tabular}{lccccccccccc}
\hline \multirow{2}{*}{ Porta-enxerto* } & \multicolumn{1}{c}{ Porcentagem de sementes com as seguintes contagens de embriões } \\
\cline { 2 - 12 } & 1 & 2 & 3 & 4 & 5 & 6 & 7 & 8 & 9 & 10 \\
\hline Trifoliata 'Flying Dragon' & 68 & 30 & 2 & 0 & 0 & 0 & 0 & 0 & 0 & 0 \\
Limoeiro 'Cravo' ENA-02 & 58 & 40 & 2 & 0 & 0 & 0 & 0 & 0 & 0 & 0 \\
TSKC x CTTR-002 & 56 & 28 & 14 & 2 & 0 & 0 & 0 & 0 & 0 & 0 \\
Limoeiro 'Cravo' ENA-01 & 56 & 36 & 4 & 4 & 0 & 0 & 0 & 0 & 0 & 0 \\
Limoeiro 'Cravo' Santa Cruz & 48 & 40 & 12 & 0 & 0 & 0 & 0 & 0 & 0 & 0 \\
TSKC x (LCR x TR)-059 & 48 & 24 & 20 & 8 & 0 & 0 & 0 & 0 & 0 & 0 \\
HTR-051 & 14 & 26 & 42 & 10 & 6 & 2 & 0 & 0 & 0 & 0 \\
Tangerineira 'Sunki' Tropical & 12 & 10 & 40 & 24 & 12 & 2 & 0 & 0 & 0 & 0 \\
TSKC x CTSW-064 & 0 & 8 & 22 & 32 & 18 & 16 & 2 & 2 & 0 & 0 \\
Citrandarin 'Indio' & 2 & 16 & 12 & 6 & 24 & 16 & 12 & 8 & 4 & 0 \\
Citrandarin 'Riverside' & 0 & 4 & 16 & 30 & 32 & 6 & 6 & 4 & 0 & 4 \\
Citrandarin 'San Diego' & 0 & 2 & 4 & 14 & 28 & 14 & 12 & 16 & 6 & 4
\end{tabular}

* onde TSKC, LCR, TR, CTSW, CTTR e HTR correspondem, respectivamente, a tangerineira 'Sunki' comum, limoeiro 'Cravo',

Poncirus trifoliata, citrumelo 'Swingle', citrange ‘Troyer' e híbrido trifoliado. 
TABELA 3 - Coeficientes de correlação de Pearson entre atributos de sementes de porta-enxertos de citros. Seropédica-RJ.

\begin{tabular}{|c|c|c|c|c|c|c|}
\hline Atributos & $\mathrm{N}$ & $\mathrm{M}$ & $\mathrm{A}$ & $\mathrm{L}$ & $\mathrm{T}$ & $\mathrm{R}$ \\
\hline & \multicolumn{6}{|c|}{ Conjunto dos porta-enxertos } \\
\hline $\mathrm{N}^{\circ}$ de embriões por semente $(\mathrm{N})$ & 1,000 & $0,234^{*}$ & $0,106^{*}$ & $0,554^{*}$ & $-0,344^{*}$ & $-0,136^{*}$ \\
\hline Massa de semente (M) & & 1,000 & $0,477^{*}$ & $0,472 *$ & $-0,270 *$ & $0,167 *$ \\
\hline Altura de semente (A) & & & 1,000 & $0,303^{*}$ & $-0,245^{*}$ & $0,057^{\mathrm{ns}}$ \\
\hline Largura da semente (L) & & & & 1,000 & $-0,451 *$ & $0,002^{\mathrm{ns}}$ \\
\hline Dificuldade extração da testa $(\mathrm{T})$ & & & & & 1,000 & $-0,111 *$ \\
\hline \multirow[t]{2}{*}{$\underline{\text { Razão de cor }(\mathrm{R})}$} & & & & & & 1,000 \\
\hline & \multicolumn{6}{|c|}{ Limoeiro ‘Cravo' ENA-01 } \\
\hline $\mathrm{N}^{\circ}$ de embriões por semente $(\mathrm{N})$ & 1,000 & $0,007^{\mathrm{ns}}$ & $0,139^{\text {ns }}$ & $-0,037^{\mathrm{ns}}$ & $-0,268^{\mathrm{ns}}$ & $-0,165^{\mathrm{ns}}$ \\
\hline Massa de semente (M) & & 1,000 & $0,129^{\text {ns }}$ & $0,206^{\mathrm{ns}}$ & $-0,275^{\mathrm{ns}}$ & $0,118^{\mathrm{ns}}$ \\
\hline Altura de semente (A) & & & 1,000 & $0,240^{\mathrm{ns}}$ & $-0,092^{\mathrm{ns}}$ & $0,017^{\mathrm{ns}}$ \\
\hline Largura da semente (L) & & & & 1,000 & $-0,167^{\mathrm{ns}}$ & $0,224^{\mathrm{ns}}$ \\
\hline Dificuldade extração da testa $(\mathrm{T})$ & & & & & 1,000 & $-0,004^{\mathrm{ns}}$ \\
\hline \multirow{2}{*}{$\underline{\text { Razão de cor (R) }}$} & & & & & & 1,000 \\
\hline & \multicolumn{6}{|c|}{ Limoeiro ‘Cravo' ENA-02 } \\
\hline $\mathrm{N}^{\circ}$ de embriões por semente $(\mathrm{N})$ & 1,000 & $-0,120^{\mathrm{n}}$ & s- $0,147^{\text {ns }}$ & $-0,058^{\mathrm{ns}}$ & $-0,198^{\mathrm{ns}}$ & $-0,350 *$ \\
\hline Massa de semente $(\mathrm{M})$ & & 1,000 & $0,250^{\text {ns }}$ & $0,181^{\mathrm{ns}}$ & $-0,245^{\mathrm{ns}}$ & $0,101^{\mathrm{ns}}$ \\
\hline Altura de semente (A) & & & 1,000 & $0,254^{\mathrm{ns}}$ & $0,010^{\mathrm{ns}}$ & $0,075^{\mathrm{ns}}$ \\
\hline Largura da semente (L) & & & & 1,000 & $0,136^{\mathrm{ns}}$ & $-0,195^{\mathrm{ns}}$ \\
\hline Dificuldade extração da testa $(\mathrm{T})$ & & & & & 1,000 & $0,126^{\text {ns }}$ \\
\hline \multirow[t]{2}{*}{ Razão de cor (R) } & \multirow{2}{*}{\multicolumn{6}{|c|}{ Limoeiro 'Cravo Santa Cruz' }} \\
\hline & & & & & & \\
\hline $\mathrm{N}^{\circ}$ de embriões por semente $(\mathrm{N})$ & 1,000 & $0,044^{\mathrm{ns}}$ & $0,368^{*}$ & $0,048^{\mathrm{ns}}$ & $0,188^{\mathrm{ns}}$ & $-0,386^{*}$ \\
\hline Massa de semente (M) & & 1,000 & $0,066^{\text {ns }}$ & $-0,106^{\mathrm{ns}}$ & $0,083^{\text {ns }}$ & $0,150^{\text {ns }}$ \\
\hline Altura de semente (A) & & & 1,000 & $0,147^{\mathrm{ns}}$ & $0,112^{\mathrm{ns}}$ & $-0,229^{\mathrm{ns}}$ \\
\hline Largura da semente (L) & & & & 1,000 & $0,016^{\mathrm{ns}}$ & $-0,176^{\mathrm{ns}}$ \\
\hline Dificuldade extração da testa $(\mathrm{T})$ & & & & & 1,000 & $-0,244^{\mathrm{ns}}$ \\
\hline \multirow{2}{*}{$\underline{\text { Razão de cor }(\mathrm{R})}$} & & & & & & 1,00 \\
\hline & \multicolumn{6}{|c|}{ Tangerineira 'Sunki Tropical' } \\
\hline $\mathrm{N}^{\circ}$ de embriões por semente $(\mathrm{N})$ & 1,000 & $-0,118^{\mathrm{n}}$ & $-0,039^{\text {ns }}$ & $-0,018^{\mathrm{ns}}$ & $0,076^{\mathrm{ns}}$ & $0,182^{\text {ns }}$ \\
\hline Massa de semente (M) & & 1,000 & $0,025^{\text {ns }}$ & $-0,003^{\mathrm{ns}}$ & $0,118^{\mathrm{ns}}$ & $0,016^{\mathrm{ns}}$ \\
\hline Altura de semente (A) & & & $1,000^{\text {ns }}$ & $0,174^{\mathrm{ns}}$ & $0,003^{\mathrm{ns}}$ & $-0,206^{\mathrm{ns}}$ \\
\hline Largura da semente $(\mathrm{L})$ & & & & 1,000 & $-0,308^{*}$ & $0,012^{\text {ns }}$ \\
\hline Dificuldade extração da testa $(\mathrm{T})$ & & & & & 1,000 & $0,101^{\mathrm{ns}}$ \\
\hline \multirow[t]{2}{*}{$\underline{\text { Razão de cor (R) }}$} & & & & & & 1,000 \\
\hline & \multicolumn{6}{|c|}{ Trifoliata 'Flying Dragon' } \\
\hline $\mathrm{N}^{\circ}$ de embriões por semente $(\mathrm{N})$ & 1,000 & $0,043^{\mathrm{ns}}$ & $-0,081^{\text {ns }}$ & $-0,196^{\mathrm{ns}}$ & $-0,058^{\mathrm{ns}}$ & \\
\hline Massa de semente (M) & & 1,000 & $0,261^{\mathrm{ns}}$ & $-0,105^{\mathrm{ns}}$ & $-0,056^{\mathrm{ns}}$ & \\
\hline Altura de semente (A) & & & 1,000 & $0,085^{\mathrm{ns}}$ & $-0,139^{\mathrm{ns}}$ & \\
\hline Largura da semente (L) & & & & 1,000 & $-0,073^{\text {ns }}$ & \\
\hline Dificuldade extração da testa $(\mathrm{T})$ & & & & & 1,000 & \\
\hline Razão de cor (R) & & & & & & 1,000 \\
\hline
\end{tabular}

Coeficientes seguidos de * e ns são, respectivamente, significativos ou não, a $5 \%$ de probabilidade. 
TABELA 3 - (continuação) - Coeficientes de correlação de Pearson entre caracteres de sementes de portaenxertos de citros. Seropédica-RJ, 2010.

\begin{tabular}{|c|c|c|c|c|c|c|}
\hline Atributos & $\mathrm{N}$ & $\mathrm{M}$ & $\mathrm{A}$ & $\mathrm{L}$ & $\mathrm{T}$ & $\mathrm{R}$ \\
\hline & \multicolumn{6}{|c|}{ Citrandarin 'Indio' } \\
\hline$\overline{\mathrm{N}^{\circ} \text { de embriões por semente }(\mathrm{N})}$ & 1,000 & $0,080^{\mathrm{ns}}$ & $0,009^{\text {ns }}$ & $0,161^{\mathrm{ns}}$ & $-0,064^{\mathrm{ns}}$ & $0,667^{*}$ \\
\hline Massa de semente $(\mathrm{M})$ & & 1,000 & $0,067^{\text {ns }}$ & $0,007^{\mathrm{ns}}$ & $0,148^{\text {ns }}$ & $-0,080^{\mathrm{ns}}$ \\
\hline Altura de semente (A) & & & 1,000 & $0,221^{\mathrm{ns}}$ & $-0,019^{\text {ns }}$ & $0,074^{\text {ns }}$ \\
\hline Largura da semente (L) & & & & 1,000 & $0,086^{\text {ns }}$ & $0,361^{*}$ \\
\hline Dificuldade extração da testa $(\mathrm{T})$ & & & & & 1,000 & $-0,243^{\text {ns }}$ \\
\hline \multirow[t]{2}{*}{ Razão de cor $(\mathrm{R})$} & & & & & & 1,000 \\
\hline & \multicolumn{6}{|c|}{ Citrandarin 'Riverside' } \\
\hline $\mathrm{N}^{\circ}$ de embriões por semente $(\mathrm{N})$ & $\overline{1,000}$ & $0,107^{\text {ns }}$ & $0,048^{\text {ns }}$ & $0,163^{\text {ns }}$ & $-0,047^{\mathrm{ns}}$ & $-0,562^{*}$ \\
\hline Massa de semente (M) & & 1,000 & $0,282 *$ & $0,286^{*}$ & $-0,075^{\text {ns }}$ & $-0,164^{\mathrm{ns}}$ \\
\hline Altura de semente (A) & & & 1,000 & $0,139^{\text {ns }}$ & $-0,025^{\mathrm{ns}}$ & $-0,225^{\mathrm{ns}}$ \\
\hline Largura da semente (L) & & & & 1,000 & $-0,058^{\mathrm{ns}}$ & $-0,063^{\text {ns }}$ \\
\hline Dificuldade extração da testa $(\mathrm{T})$ & & & & & 1,000 & $0,089^{\text {ns }}$ \\
\hline \multirow[t]{2}{*}{ Razão de cor (R) } & & & & & & 1,000 \\
\hline & \multicolumn{6}{|c|}{ Citrandarin 'San Diego' } \\
\hline$\overline{\mathrm{N}^{\circ} \text { de embriões por semente }(\mathrm{N})}$ & 1,000 & $0,346^{*}$ & $0,233^{\text {ns }}$ & $0,126^{\text {ns }}$ & $-0,240^{\mathrm{ns}}$ & $-0,166^{\mathrm{ns}}$ \\
\hline Massa de semente (M) & & 1,000 & $0,117^{\text {ns }}$ & $0,370 *$ & $-0,249^{\mathrm{ns}}$ & $-0,054^{\mathrm{ns}}$ \\
\hline Altura de semente (A) & & & 1,000 & $0,182^{\text {ns }}$ & $0,192^{\text {ns }}$ & $0,172^{\text {ns }}$ \\
\hline Largura da semente (L) & & & & 1,000 & $-0,048^{\mathrm{ns}}$ & $0,159^{\text {ns }}$ \\
\hline Dificuldade extração da testa $(\mathrm{T})$ & & & & & 1,000 & $0,061^{\mathrm{ns}}$ \\
\hline \multirow[t]{2}{*}{ Razão de cor $(\mathrm{R})$} & & & & & & 1,000 \\
\hline & \multicolumn{6}{|c|}{ HTR-051 } \\
\hline$\overline{\mathrm{N}^{\circ} \text { de embriões por semente }(\mathrm{N})}$ & 1,000 & $-0,026^{\text {ns }}$ & $0,305^{*}$ & $0,046^{\text {ns }}$ & $0,013^{\text {ns }}$ & $-0,311 *$ \\
\hline Massa de semente (M) & & 1,000 & $0,234^{\text {ns }}$ & $0,144^{\text {ns }}$ & $0,022^{\text {ns }}$ & $0,238^{\mathrm{ns}}$ \\
\hline Altura de semente (A) & & & $1,000^{\text {ns }}$ & $0,025^{\text {ns }}$ & $0,024^{\mathrm{ns}}$ & $-0,124^{\mathrm{ns}}$ \\
\hline Largura da semente (L) & & & & 1,000 & $0,040^{\mathrm{ns}}$ & $0,204^{\mathrm{ns}}$ \\
\hline Dificuldade extração da & & & & & 1,000 & $0,125^{\mathrm{ns}}$ \\
\hline \multirow[t]{2}{*}{ Razão de cor (R) } & \multirow{2}{*}{\multicolumn{6}{|c|}{ TSKC $x$ (LCR x TR)-059 }} \\
\hline & & & & & & \\
\hline $\mathrm{N}^{\circ}$ de embriões por semente $(\mathrm{N})$ & 1,000 & $-0,017^{\text {ns }}$ & $0,218^{\text {ns }}$ & $0,030^{\text {ns }}$ & $-0,257^{\mathrm{ns}}$ & $0,148^{\text {ns }}$ \\
\hline Massa de semen & & 1,000 & $-0,344 *$ & $0,079^{\text {ns }}$ & $0,146^{\mathrm{ns}}$ & $0,231^{\mathrm{ns}}$ \\
\hline Altura de seme & & & 1,000 & $0,168^{\text {ns }}$ & $-0,037^{\mathrm{ns}}$ & $-0,121^{\mathrm{ns}}$ \\
\hline Largura da semente (L) & & & & 1,000 & $0,215^{\mathrm{ns}}$ & $0,095^{\mathrm{ns}}$ \\
\hline Dificuldade extração da & & & & & 1,000 & $-0,074^{\mathrm{ns}}$ \\
\hline \multirow[t]{2}{*}{ Razão de cor (R) } & & & & & & 1,000 \\
\hline & \multicolumn{6}{|c|}{ TSKC x CTSW-064 } \\
\hline$\overline{\mathrm{N}^{\circ} \text { de e }}$ & 1,000 & $-0,246^{\text {ns }}$ & $0,093^{\text {ns }}$ & $0,097^{\text {ns }}$ & $-0,227^{\mathrm{ns}}$ & $-0,330 *$ \\
\hline Massa de s & & 1,000 & $-0,024^{\mathrm{ns}}$ & $0,030^{\text {ns }}$ & $0,022^{\mathrm{ns}}$ & $0,093^{\text {ns }}$ \\
\hline Altura de semente (A) & & & 1,000 & $0,155^{\text {ns }}$ & $0,138^{\text {ns }}$ & $-0,002^{\mathrm{ns}}$ \\
\hline Largura da semente (L) & & & & 1,000 & $0,096^{\mathrm{ns}}$ & $-0,139^{\text {ns }}$ \\
\hline Dificuldade extração da & & & & & 1,000 & $0,049^{\text {ns }}$ \\
\hline \multirow[t]{2}{*}{ Razão de cor (R) } & & & & & & 1,000 \\
\hline & \multicolumn{6}{|c|}{ TSKC x CTTR-002 } \\
\hline$\overline{\mathrm{N}^{\circ} \text { de embriõe }}$ & 1,000 & $-0,117^{\text {ns }}$ & $-0,055^{\text {ns }}$ & $0,072^{\text {ns }}$ & $0,247^{\mathrm{ns}}$ & $-0,050^{\mathrm{ns}}$ \\
\hline Massa de semente (M) & & 1,000 & $0,242^{\text {ns }}$ & $0,058^{\text {ns }}$ & $0,078^{\mathrm{ns}}$ & $0,202^{\mathrm{ns}}$ \\
\hline Altura de semente (A) & & & 1,000 & $0,144^{\text {ns }}$ & $-0,003^{\mathrm{ns}}$ & $0,259^{\text {ns }}$ \\
\hline Largura da semente (L) & & & & 1,000 & $0,231^{\mathrm{ns}}$ & $0,061^{\mathrm{ns}}$ \\
\hline Dificuldade extração da testa $(\mathrm{T})$ & & & & & 1,000 & $0,242^{\text {ns }}$ \\
\hline Razão de cor (R) & & & & & & 1,000 \\
\hline
\end{tabular}

Coeficientes seguidos de * e ${ }^{\text {ns }}$ são, respectivamente, significativos ou não, a $5 \%$ de probabilidade. 


\section{CONCLUSÕES}

1- Há maior dificuldade de extração da testa em sementes de citros de menor tamanho.

2 - As relações entre poliembrionia e caracteres de tamanho de semente variam com o genótipo de citros.

3 - Na maioria dos genótipos de citros avaliados, o número de embriões por semente correlaciona-se negativamente à razão de cor, sugerindo que a análise de coloração de sementes inteiras seria uma ferramenta alternativa para a avaliação visual rápida da poliembrionia.

\section{REFERÊNCIAS}

ANDRADE, R.A.; MARTINS, A.B.G.; LEMOS, E.G.M.; LUZ, F.J.F; SILVA, M.T.H. Detecção de polimorfismo em porta-enxertos para citros. Revista Brasileira de Fruticultura, Jaboticabal, v.29, n.2, p.345-349, 2007.

ALESA, P.; JUÁREZ, J.; OLlitraulT, P.; NAVARRO, L. Polyembryony in non-apomictic citrus genotypes. Annals of Botany, Exeter, v.106, n4, p.533-545, 2010.

BOWMAN, K.D.; GMITTER, F.G.; HU, X.L. Relationships of seed size and shape with polyembryony and the zygotic or nucellar origin of Citrus spp. seedlings. HortScience, Alexandria, v.30, n.6, p.1279-1282, 1995.

CASTLE, W.S. A review of citrus seed biology and its relationship to nursery practices. In: INTERNATIONAL CITRUS CONGRESS, 4., 1981, Tokyo. Proceedings... Tokyo: International Society of Citriculture, 1981. v.1, p.113-119.

GARCÍA, R.; ASÍNS, M.J.; FORNER, J.; CARBONELL, E.A. Genetic analysis of apomixis in Citrus and Poncirus by moleculars markers. Theoretical and Applied Genetics, Berlin, v.99, p.511-518, 1999.

JASKANI, M.J.; ABBAS, H.; KHAN, M.M.; SHAHZAD, U.; HUSSAIN, Z. Morphological description of three potential citrus rootstocks. Pakistan Journal of Botany, Karachi, v.38, n.2, p. 311-317, 2006.
MOREIRA, R.A.; RAMOS, J.D.; CRUZ, M.C.M. Caracterização de frutos e poliembrionia em sementes de 'Flying Dragon' e de híbridos de porta-enxerto de citros. Revista Brasileira de Fruticultura, Jaboticabal, v.32, n.2, p.486-492, 2010.

NEVES, M.F.; TROMBIN, V.G.; MILAN, P.; LOPES, F.F.; CRESSONI, F.; KALAKI, R. O retrato da citricultura brasileira. Ribeirão Preto: Markestrat, 2010. 138 p.

PASSOS, O.S.; PEIXOUTO, L.S.; SANTOS, L.C.; CALDAS, R.C.; SOARES FILHO, W.S. Caracterização de híbridos de Poncirus trifoliata e de outros porta-enxertos de citros no estado da Bahia. Revista Brasileira de Fruticultura, Jaboticabal, v.28, n.3, p.410-413, 2006.

POMPEU JUNIOR, P. Porta-enxertos. In: MATTOS JUNIOR, D.; NEGRI, J.D.; PIO, R.M.; POMPEU JUNIOR, P. Citros. Campinas: Instituto Agronômico de Campinas/ Fundag, 2005. p.63-104.

SCHÄFER, G.; SOUZA, P.V.D.; DAUDT, R.H.S.; DORNELLES, A.L.C. Substratos na emergência de plântulas e expressão da poliembrionia em portaenxertos de citros. Ciência Rural, Santa Maria, v.35, n.2, p.471-474, 2005.

SHUNYUAN, X.; WENCAI, Z.; JISHENG, C. Segregation and inheritance of a few morphological and physiological traits in the progeny of Huanong Bendizao x Ichang Papeda. South China Fruits, Beijing, v.4, 1994.

SOARES FILHO, W.S.; DIAMANTINO, M.S.A.S.; MOITINHO, E.D.B.; CUNHA SOBRINHO, A.P.; PASSOS, O.S. 'Tropical': uma nova seleção de tangerina 'Sunki'. Revista Brasileira de Fruticultura, Jaboticabal, v.24, n.1, p.127-132, 2002.

SOARES FILHO, W.S.; MOREIRA, C.S.; CUNHA, M.A.P.; CUNHA SOBRINHO, A.P.; PASSOS, O.S. Poliembrionia e freqüência de híbridos em Citrus spp. Pesquisa Agropecuária Brasileira, Brasília, v. 35 , n. 4 , p. $857-864,2000$. 
SOARES FILHO, W.S.; VILARINHOS, A.D.; ALVES, A.A.C.; CUNHA SOBRINHO, A.P.; OLIVEIRA, A.A.R.; SOUZA, A.S.; LEDO, C.A.S.; CRUZ, J.L.; SOUZA, L.D.; CASTRO NETO, M.T.; GUERRA FILHO, M.S.; PASSOS, O.S.; MEISSNER FILHO, P.E. Programa de melhoramento genético de citros da Embrapa mandioca e fruticultura: obtenção de híbridos. Cruz das Almas: Embrapa Mandioca e Fruticultura, 2003. 37p. (Série Documentos, 106).

UENO, I.; HIRAI, M. Identification of zygotic embryos in polyembryonic citrus seeds by cotiledon colour. Bulletin of the Fruit Tree Research Station, Tsukuba-Shi, v.10, p.35-49, 1983.
VÁSQUEZ ARAUJO, J.E.; SOARES FILHO, W. dos S.; CUNHA, M.A.P. da; CUNHA SOBRINHO, A.P. da; PASSOS, O.S.; SOUZA, A. da S. Identification of zygotic embryos in polyembryonic citrus seeds: the use of cotyledon colours. In: INTERNATIONAL CITRUS CONGRESS, 7., 1992, Acireale, Italy. Proceedings... Catania: International Society of Citriculture, 1994. v.1, p.142-144. 